\title{
《招待講演》
}

\section{The Use of Exercise in Assessing Children with Cerebral Palsy}

\author{
Oded Bar-Or*
}

\section{Introduction}

The last two decades have seen a major increase in knowledge about pediatric exercise medicine. Information has been accumulating on the relevance of physical activity, or inactivity, to children's health and the use of exercise as an assessment tool. The objective of this presentation is to review current concepts on the rationale for, and methodological aspects of, exercise testing of children and adolescents with cerebral palsy (CP). For more details see Ref. 1).

\section{Why Exercise Testing?}

There are two main reasons for exercise testing in the child with $\mathrm{CP}$ : determination of physical fitness and a assessment of effects of therapy. Children with any chronic disease or physical disability are often insufficiently active. ${ }^{3)}$ This is also true for the child with $\mathrm{CP}$, whose activity level and daily energy expenditure are considerably lower than in healthy children. One reason for such hypoactivity is the patient's low physical fitness. By measuring specific components of fitness one can discover specific causes of limitation in a patient's daily motor performance. The second use of the exercise laboratory is to assess the effect of treatments such as orthoses, surgery, rehabilitation, or medication on the child's motor function. Traditional clinical methods to assess motor function, such as manual examination of muscle strength, are subjective and often unreliable. The exercise laboratory can provide objective, standardized and highly reliable measurements.

\section{What Should We Measure?}

One should focus on physiologic functions that have clinical relevance to the child's motor ability. The three main functions to be measured are energy cost of locomotion, local muscle endurance and muscle strength. Energy Cost of Locomotion. Because patients with CP, particularly with spastic diplegia, have abnormal gait, their energy cost of locomotion is excessive. For a given walking speed, some patients require three times as much energy as do able-bodied controls. This is the main reason why these children fatigue easily. The high metabolic energy cost reflects high mechanical cost and excessive cocontraction of antagonist muscles. ${ }^{6}$ Reduction of the metabolic cost of locomotion should be a therapeutic objective and be tested before and after therapy. For example, one of the effects of ankle-foot orth-

\footnotetext{
* Children's Exercise \& Nutrition Centre, McMaster University, Hamilton, Ontario, Canada
} 
osis is a reduction of $5-6 \%$ in the energy cost of walking (unpublished data from the author's laboratory). Local muscle endurance is the ability to resist fatigue by performing repeated high-intensity contraction. A test of this function (The Wingate Anaerobic Test-WAnT) has been found feasible and highly reliable for chil dren with $\mathrm{CP}$ and other disabilities. ${ }^{5)}$ Among children with $\mathrm{CP}$, performance in the WAnT is correlated with components of the Gross Motor Function Measure, ${ }^{4)}$ which suggests that this test is relevant to the child's daily activity. Muscle strength (the highest force generated during voluntary contraction) is deficient in patients with $\mathrm{CP}$. Of particular importance is the imbalance in strength between antagonistic muscle groups, e.g., quadriceps vs hamstrings, which may affect the child's locomotion and other motor abilities. ${ }^{2}$ ) There is a need for more research on the clinical importance of muscle weakness, strength imbalance and the effect of strength training on motor ability of the child with $\mathrm{CP}$.

\section{Conclusion}

In conclusion, exercise testing can open interesting possibilities to the clinician who is interested in factors that limit functional abilities of children with $\mathrm{CP}$ and the effects of various interventions on such abilities.

\section{References}

1) Bar-Or O : Role of exercise in assessment and management of neuromuscular disease in children. Med Sci Sports Exerc 1996; 28 : 421-427

2) Damiano DL, Kelly LE, Vaughn CL: Effects of quadriceps femoris muscle strengthening on crouch gait in children with spastic diplegia. Phys Ther $1995 ; 75$ : 658-671

3) Longmuir PE, Bar-Or O : Physical activity of children and adolescents with a disability: methodology and effects of age and gender. Pediatr Exerc Sci $1994 ; 6$ : 168-177

4) Parker DF, Carriere L, Hebestreit H, Salsberg A, Bar-Or O: Muscle performance and gross motor function in children with spastic cerebral palsy. Devel Med \& Child Neurol 1993; 35 : 17-23

5) Tirosh E, Rosenbaum P, Bar-Or O: A new muscle power test in neuromuscular disease: feasibility and reliability. Am J Dis Child 1990 ; 144 : 1083-1087

6) Unnithan V, Dowling J, Frost G, Bar-Or O : Role of cocontraction in the $\mathrm{O}_{2}$ cost of walking in children with cerebral palsy. Med Sci Sports Exerc 1996; 28 : $1498-1504$ 